\title{
(2) OPEN ACCESS \\ Managing enduring public health emergencies such as COVID-19: lessons from Uganda Red Cross Society's Ebola virus disease response operation
}

\author{
Daniel Geiger $\odot,{ }^{1}$ Lisa Harborth, ${ }^{1}$ Alex Mugyisha ${ }^{2}$
}

\begin{abstract}
${ }^{1}$ University of Hamburg Faculty of Business, Economics and Social Sciences, Hamburg, Germany

${ }^{2}$ Uganda Red Cross Society, Kampala, Uganda
\end{abstract}

\section{Correspondence to}

Professor Daniel Geiger, University of Hamburg Faculty of Business, Economics and Social Sciences, Hamburg 20146,

Germany;

daniel.geiger@uni-hamburg.de

Received 27 March 2020 Revised 23 April 2020 Accepted 23 April 2020 Published Online First 6 May 2020

\section{A}

ABSTRACT

Background In this piece, we translate insights from our study of routine coordination in the Ebola virus disease response operation by Uganda Red Cross Society (URCS) for managing long-lasting public health emergencies. We further show how these lessons are relevant to the severe acute respiratory syndrome coronavirus 2 (SARS-CoV-2) pandemic. Commonly, emergency response organisations, like the URCS or hospitals, are ill equipped to handle longer lasting emergencies. These emergencies require special measures that combine ad-hoc action, continuous awareness over longer time periods, and the collaboration of multiple actors such as the government, public health institutions and other non-governmental organisations (NGOs). Results From our study we can translate seven lessons learnt which are important for managing long-term public health emergencies such as pandemics: (1) centralised pooling and management of resources; (2) engagement of local communities in response efforts;

(3) the need to continuously recruit and train staff; (4) the establishment of adjusted working patterns to prevent staff exhaustion; (5) cooperation of involved agencies with security for enforcing measures; (6) the revision of funding frameworks; and (7) the use of global positioning system (GPS) data to identify population movement patterns.

Conclusion Although still speculative at this stage, we apply these lessons to the current SARS-CoV-2 pandemic. We argue that immediate action in the areas of resource pooling and control over critical resources, in the engagement of trusted and respected individuals in risk communication, in the continuous training and hiring of new staff, and in the appropriation of GPS tracking data is called for in managing SARS-CoV-2 by policy makers, NGOs and other involved agencies.

\section{INTRODUCTION}

The purpose of the paper is to translate research from the Ebola virus disease (EVD) response operation implemented by the Uganda Red Cross Society (URCS) to more general insights about the management of long-term public health emergencies. The lessons build on data that we collected as part of a larger study of the temporal coordination of routines in emergency response operations of URCS. We further speculate about how these lessons might apply to addressing the current severe acute respiratory syndrome coronavirus 2 (SARS-CoV-2) pandemic. Long-lasting public health emergencies like the current SARS-CoV-2 pandemic present healthcare organisations and key decision-makers with very specific challenges they are commonly not prepared for. ${ }^{1}$ Most disaster contingency and preparedness plans focus on short-term emergencies that can be managed and mitigated over relatively limited time periods. ${ }^{2}$

\section{Study}

Our original study, undertaken in July 2019 at Mpondwe and neighbouring points of entries (PoEs), is part of a larger, 3-year research engagement with URCS on routine coordination in response and emergency settings. As part of the study, we conducted non-participant observation of URCS' EVD operation, particularly by studying the activities at 18 out of 20 PoEs over a 15-day period. In addition, we conducted 22 extensive interviews with URCS staff from all levels, attended seven interagency coordination meetings in Kasese District, and collected supplementary materials such as situation reports and press releases. This paper does not present primary data from this study but offers a translation of the key lessons for the current pandemic response.

\section{Context}

EVD is a severe illness with high fatality rates, spreading through direct contact with bodily fluids. ${ }^{3}$ During the outbreak in the Democratic Republic of Congo (DRC) and neighbouring countries, the disease was treated with an experimental vaccination, which in prior studies has been proven highly effective with up to $100 \%$ efficacy. ${ }^{4}$

The outbreak in East Africa started in August 2018 with several cases in the province of North Kivu in DRC. ${ }^{5}$ With just around 30 kilometres between the outbreak's epicentre and the Ugandan border, the Ugandan society was facing a high risk of infection. In June 2019, the Ugandan Ministry of Health confirmed the first three cases of EVD in Kasese District, Western Uganda. ${ }^{6}$ At the time of writing, these were the only confirmed fatalities of EVD in Uganda, with however 2264 EVD fatalities in neighbouring DRC. ${ }^{7}$

At Mpondwe PoE in Kasese District, the border is porous and highly frequented. During market days, taking place twice a week, up to 30000 people cross the border per day. Here and at other 19 locations, URCS has been conducting screening procedures since August 2018. The task is to monitor people crossing the border for EVD symptoms in order to isolate suspects and prevent them from entering the country. Within the scope of the Ugandan National EVD Response Plan, URCS also
To cite: Geiger D, Harborth L Mugyisha A. BMJ Leader 2020:4:113-116. 
engages in community awareness and sensitisation campaigns about EVD.

\section{Core problem of long-lasting public health emergencies}

Commonly, emergency response organisations such as the URCS are prepared and have the capacity to quickly respond to shortterm emergencies such as floods, landslides or draught. ${ }^{8}$ Hospitals generally plan and prepare for mass casualties, where a large number of injured people need to be treated for a short period of time, for example after large road traffic accidents. Efficient response in such emergencies requires rapid assessment, a sound triage, timely mobilisation of first responders and quick provision of essential items for victims. ${ }^{9}$

The EVD response operation brought entirely new challenges to URCS and other involved agencies. Responding to emergencies over extended time periods required novel approaches on many levels, and URCS had to find workable solutions. Although the current SARS-CoV-2 pandemic is unfolding at the time of writing, we believe that some of these insights could still inform current management and decision-making.

\section{KEY LESSONS LEARNT FOR MANAGING LONGER LASTING PUBLIC HEALTH EMERGENCIES LIKE EPIDEMICS}

Based on our study of the URCS operation in fighting EVD, we are able to translate the following key lessons for managing longer term public health emergencies related to such dangerous epidemics. The lessons are meant to inform key decision-makers working in governments, emergency management operations, hospitals and non-governmental organisations (NGOs).

\section{Centralised pooling and management of resources}

In the EVD response operation, the local government of Kasese District had access to resources of all involved partners and could allocate them according to the needs of the situation. NGOs were only allowed to join the operation if they formally committed to share their resources, particularly cars, trucks, equipment and qualified staff. All resources were controlled by the district commander, who allocated them each morning to the tasks, which were given priority on the day. This proved to be a necessary and critical decision for the operation's success, since it ensured that resources were available according to the priorities of the overall operation. Commonly, humanitarian aid organisations are used to work on their own, sometimes even in competition with each other. ${ }^{11}{ }^{11}$ The resulting lack of cooperation can be addressed by a centralised pooling of resources. Central oversight and command with respect to available resources is an important precondition and an effective response to the enduring challenges of long-lasting health emergencies.

For the current SARS-CoV-2 pandemic, these insights offer important lessons. Although our knowledge is still quite limited, a number of factors already show up as crucial when it comes to resources: lack of protective gear and disinfectants in healthcare facilities and the highly increased prices due to increased demand are good examples of missing resource pools. ${ }^{12}$ A successful management of the SARS-CoV-2 pandemic could benefit from centrally managed allocation of these and other critical material resources. Capacities of intensive care units in hospitals and personnel resources could be included as well, in order to allocate them effectively. This would require a central database and generally accessible repositories to ensure oversight.

\section{Engagement of local communities in response efforts}

URCS put great emphasis on employing volunteers from local communities to carry out sensitive tasks such as risk communication. These volunteers were trusted members of the communities and received specific training (see lesson 3). This enabled them to speak about sensitive health-related issues and ensured a tailored approach of communication, which was well received. Such a community-based approach was instrumental to the successful change of healthcare practices such as hand washing, safe and dignified burials, or social distancing. In addition, volunteers were invited to radio broadcasts and hosted question and answer sessions to inform the public about EVD. In longer term public health emergencies, it is critical that affected local communities are closely involved in the response efforts. Hence, policy makers and NGOs need to collaborate with trusted members of local communities and engage them in the operation. This bottom-up approach engenders wider trust, ensures the messages spread in appropriate ways and helps in containing misinformation-all of which are particularly important in emergencies.

For the current SARS-CoV-2 pandemic, community engagement on all levels of society seems to be fundamental as well, especially as compliance with the introduced measures is expected from the entire population. The shutdown of public life entails significant behavioural changes, which can only be implemented if people actually understand them. ${ }^{13}$ Therefore, authorities should closely engage members of local communities. These could be represented by mayors or managers of corporations, but also by teachers and even by social media influencers or other celebrities. They are considered to be persons of respect, enjoying certain levels of trust, and they speak the language of their peers. This enables them to act as role models, to spread the message and to raise awareness, apart from national politicians and more classic media outlets.

\section{Continuous training of existing and new staff}

Fundamentally important to the success of the EVD operation was the continuous training of volunteers. URCS launched an intensive training programme in all branches that were involved in the EVD operation. This training ensured that the local volunteers had a high set of practical skills and the necessary knowledge about EVD. Due to the long-lasting nature of the operation, URCS had to continuously recruit new volunteers, who needed to be trained for the operation as well. Establishing regular, local trainings not only provided an answer to these challenges, but also increased the staff's motivation. However, running trainings alongside the ongoing operation proved to be quite demanding since sufficient training resources needed to be available.

For addressing the SARS-CoV-2 pandemic, this lesson is important in at least two ways. First, as knowledge on the disease is still emerging, healthcare staff need to be trained and provided with the latest knowledge on a continuous basis. Centralised knowledge-sharing platforms could facilitate dissemination of most up-to-date information. Second, as hospitals and other areas of critical infrastructure are already overwhelmed ${ }^{14}$ and in need of additional staff and volunteers, hiring new staff and developing the capability to train them accordingly are of crucial importance. Implementing onsite and off-site training in hospitals and other institutions that are undertaken while the emergency is ongoing is indispensable to prevent staff shortages. Hence, preparedness and response plans need to encompass training schemes for staff, and resources for conducting trainings need to be made available while the operation is ongoing. ${ }^{15}$

\section{Adjust working patterns to prevent staff exhaustion}

The long-term nature of the EVD operation required URCS to adjust the working patterns of staff to prevent exhaustion and 
fatigue. Many volunteers worked in exceptionally long 12 -hour shifts 7 days a week for several months, while having to remain focused, alert and vigilant in stressful environments under high pressure. This resulted in an eventual decrease in motivation and alertness, jeopardising the operation's effectiveness. Moreover, volunteers suffered from the psychological strains of the situation. The EVD operation demonstrated that the common ways of working, adequate to respond to short-term disasters, needed to be changed under those long-term conditions. URCS experimented with implementing a shift system and introducing the possibility of alternating between different tasks to fight fatigue and boredom. Contingency plans needed to be established to replace personnel in case of illnesses or annual leave, and psychosocial support teams were implemented to help the volunteers. Therefore, response plans to long-term health emergencies should include measures to protect not only the staff's physical but also their psychological well-being. This can be achieved by the implementation of shift systems, workplace rotations and psychosocial support structures.

As the COVID-19 pandemic is unfolding rapidly, all affected institutions have to be prepared for worst-case scenarios. Personnel are already burned out and need replacement. ${ }^{14} \mathrm{~A}$ swift reassignment of staff could help in quickly mitigating this situation. Employees of public institutions could be removed from their present jobs and provide support in non-critical parts of hospitals or other healthcare facilities, thus freeing up more qualified staff for core tasks. Moreover, volunteers should be recruited to provide support in non-critical areas of patient treatment and logistical support. This again requires training as outlined above. In addition, psychosocial support capacity for those working on the front lines seems to be pivotal to ensure the well-being, motivation and durability of staff over extended time periods.

\section{Close cooperation with security for enforcing measures}

In the EVD case, ensuring secure work environments and enforcing screening procedures could only be accomplished by police and border protection forces. URCS needed to keep a necessary distance from military or police forces to be perceived as an independent actor. Because of its mandate, URCS is generally not allowed to enforce procedures in situations of conflict and non-compliance. However, while remaining independent and compliant with their mandate, URCS staff closely collaborated with the national police and the military to ensure appropriate behaviour and the settlement of conflicts. As our study showed, implementing new policies and behavioural changes sometimes required the exercise of bolder measures, which NGOs and other agencies are not able and not mandated to carry out. Response plans should therefore establish communication channels and list contact persons between NGOs, agencies and security forces in order to ensure a close and swift cooperation if needed.

Translating these lessons to the current SARS-CoV-2 pandemic shows how crucial a close cooperation between agencies and police and border protection forces is. First, it needs to be ensured that all actors act on similar guidelines and policies to avoid confusion in the public. This requires a centrally communicated set of measures all actors know about. Second, the situation shows that enforcing behaviour is sometimes critical to prevent non-compliance. It is important that, for example, hospitals have a contact person within security forces such as the police with whom they liaise closely to monitor the situation. Security personnel need to be involved in the risk communication parts of the staff training, as well as to ensure that both parties understand each other's constraints and measures to enable a consistent behaviour throughout.

\section{Revision of funding frameworks}

A significant problem for URCS' EVD response operation resulted from the short-term nature of common disaster response funding. URCS staff continuously had to write proposals and requests to extend funding frameworks, thereby absorbing resources that were needed in the actual response operation. Due to short planning cycles, volunteers engaged in the operation could not be employed long enough to secure the full implementation of all measures over the whole time. This in turn created a higher demand for hiring and training new volunteers (see lesson 3). Hence, policy makers and NGOs need to develop different funding frameworks that are particularly suited to address longer lasting emergencies. They require frameworks that allow for more flexibility in spending, funding extensions and longer funding periods. The short-term nature of current disaster funding is counterproductive to the provision of enduring disaster relief.

Similar observations can already be made in the SARS-CoV-2 pandemic response. Governments and other funding bodies are opening up new funds to support critical infrastructure. However, most funds still have a very short-term focus and can cover only the immediate needs for a few weeks. This stipulates insecurity on the side of the benevolents, and occupies critical resources for proposal writing and application. Hence, providing funding frameworks that cover a longer term horizon would significantly support effective response measures over sustained periods of time.

\section{Use of GPS data to identify population movement patterns}

One critical aspect of the EVD operation was to closely screen people who move into the country. However, as the border in Kasese District is very porous, many unofficial pathways exist. In order to close these loopholes, URCS staff engaged in extensive walking tours and physical inspections to get an understanding of population movement. This procedure was very time-consuming and lacked accuracy. However, digital mapping techniques could offer a faster and more diligent mechanism, enabling interventions that are more effective. In the EVD operation, global positioning system (GPS) data from OpenStreetMap already provided a first overview of commonly used unofficial paths. Elsewhere digital mapping techniques are already used to support fast and efficient disaster response. ${ }^{16}{ }^{17}$ GPS data from people's mobile phones provide real-time information about population movements and allow identification of movement patterns. With the help of such time-sensitive data, areas of a high density of people and information on geographical activities within communities can more easily be identified.

In the current SARS-CoV-2 pandemic, GPS data could provide important information about population movements and help in better understanding how the virus spreads and who is potentially infected. These could help virologists and decision-makers to adjust response measures to certain geographical areas or to trace contact persons. However, data protection issues seem to be critical and unresolved. ${ }^{18}$ Hence, pandemic response plans need to incorporate measures to obtain digital trace data in anonymised and legal forms to make them available for research and state actors alike.

\section{CONCLUSION}

The seven key lessons, which we translated from our study of the EVD response operation, are to varying degrees fundamental to 
the immediate response to the current SARS-CoV-2 pandemic. The central pooling and management of resources seems to be of utmost importance for quickly responding to the current needs for protective gear, intensive care unit beds or ventilators. A central oversight and control over critical resources is pivotal to ensure that resources are allocated in the most efficient way. Engaging trustworthy individuals to provide support in risk communication and spread tailored messages also seems to be of high importance these days. This can significantly help in ensuring compliant behaviour of the public. Continuous training and recruitment of staff seems to be a core issue for healthcare organisations in confronting the current pandemic. Particularly seconding staff from other, non-central public agencies to support healthcare facilities and the establishment of some basic training are an important measure for the upcoming weeks. Likewise, the establishment of new working patterns to prevent staff exhaustion is an immediate measure healthcare facilities should implement in the current situation as soon as possible. Last but not least, the use of GPS tracking is currently intensively discussed as a viable measure to prevent the spread of COVID-19 across the globe. Implementing such tracking apps that ensure compliance with data protection laws is a pressing need in all affected countries in these times.

However, more research is still needed to explore how longlasting public health emergencies can be governed, coordinated and funded in sustainable and enduring ways. ${ }^{19}$ While at the time of writing it is too early to say how the SARS-CoV-2 pandemic will evolve, it is not too early to prepare for a long-lasting emergency that includes the lessons learnt from the EVD response.

\section{Twitter Daniel Geiger @Org_Studies}

Acknowledgements We gratefully acknowledge the generous support of the Uganda Red Cross Society in our data collection efforts. Without the spirit of our close and inspiring relationship, this study could not have been conducted.

Contributors DG and LH planned the study, collected and analysed the data, and wrote the manuscript. AM supported the planning of the study and coordinated data collection efforts.

Funding The authors have not declared a specific grant for this research from any funding agency in the public, commercial or not-for-profit sectors.

Competing interests None declared.

Patient consent for publication Not required.

Provenance and peer review Not commissioned; externally peer reviewed.

Open access This is an open access article distributed in accordance with the Creative Commons Attribution Non Commercial (CC BY-NC 4.0) license, which permits others to distribute, remix, adapt, build upon this work non-commercially, and license their derivative works on different terms, provided the original work is properly cited, appropriate credit is given, any changes made indicated, and the use is non-commercial. See: http://creativecommons.org/licenses/by-nc/4.0/.

\section{ORCID iD}

Daniel Geiger http://orcid.org/0000-0002-4969-2437

\section{REFERENCES}

1 Weick KE. Enacted sensemaking in crisis situations. J Manag Stud 1988;25:305-17.

2 Burkle FM. Lessons learnt and future expectations of complex emergencies. BMJ 1999;319:422-6.

3 WHO. Ebola virus disease 2020. Available: www.who.int/health-topics/ebola; [Accessed 25 Mar 2020].

4 Henao-Restrepo AM, Camacho A, Longini IM, et al. Efficacy and effectiveness of an rVSV-vectored vaccine in preventing Ebola virus disease: final results from the Guinea ring vaccination, open-label, cluster-randomised trial (Ebola Ça Suffit!). Lancet 2017;389:505-18

5 WHO. Disease outbreak news. Ebola virus disease - Democratic Republic of the Congo, 2018. Available: www.who.int/csr/don/4-august-2018-ebola-drc/en/ [Accessed 25 Mar 2020].

6 Ministry of Health Uganda. Press statement on Ebola outbreak in Kasese district, 2019. Available: www.health.go.ug/download/file/fid/2276; [Accessed 25 Mar 2020].

7 WHO. Ebola virus disease: situation reports, 2020. Available: https://www.afro.who. int/health-topics/ebola-virus-disease; [Accessed 25 Mar 2020].

8 Faraj S, Xiao Y. Coordination in fast-response organizations. Management Science 2006;52:1155-69.

9 Darkow PM. Beyond "bouncing back": Towards an integral, capabilitybased understanding of organizational resilience. J Contingen Crisis Manag 2019;27:145-56.

10 Schulman P, Roe E, Eeten Mvan, et al. High reliability and the management of critical infrastructures. J Conting Crisis Manag 2004;12:14-28.

11 Tuckman HP. Competition, commercialization, and the evolution of nonprofit organizational structures. J Policy Analysis Manag 1998;17:175-94.

12 Farsi D, Mofidi M, Mahshidfar B, et al. Consider the options; can decontamination and reuse be the answer to N95 respirator shortage in COVID-19 pandemic? Advan J Emer Med 2020.

13 Rubin GJ, Amlôt R, Page L, et al. Public perceptions, anxiety, and behaviour change in relation to the swine flu outbreak: cross sectional telephone survey. BMJ 2009;339:b2651

14 Moghadas SM, Shoukat A, Fitzpatrick MC, et al. Projecting Hospital utilization during the COVID-19 outbreaks in the United States. Proc Natl Acad Sci U S A 2020;117:9122-6.

15 Danner-Schröder A, Geiger D. Unravelling the motor of patterning work: toward an understanding of the Microlevel dynamics of standardization and flexibility. Organization Science 2016;27:633-58.

16 Qadir J, Ali A, ur Rasool R, et al. Crisis analytics: big data-driven crisis response. J Int Human Action 2016;1:12.

17 Freire S. Modeling of spatiotemporal distribution of urban population at high resolution-value for risk assessment and emergency management. In: Konecny M Zlatanova T, Bandrova TL, eds. Geographic information and cartography for risk and crisis management. Berlin, Heidelberg: Springer, 2010: 53-67.

18 lenca M, Vayena $\mathrm{E}$. On the responsible use of digital data to tackle the COVID-19 pandemic. Nat Med 2020;26:463-4.

19 Geiger D, Danner-Schröder A, Kremser W. Getting ahead of time - performing temporal boundaries to coordinate routines under temporal uncertainty. Administrative Science Quarterly 2020. forthcoming. 